\title{
Biodiversidade Marinha Brasileira: a importância da conservação marinha e o cumprimentos dos compromissos internacionais pelo Brasil
}

\author{
Brazilian marine biodiversity: the importance of marine conservation \\ and compliance with international commitments by Brazil
}

\author{
Aleph Hassan Costa Amin \\ Universidade Federal dos Pará - UFPA
}

\section{Milena Furtado Farias}

Centro Universitário Metropolitano da Amazônia

\author{
Dielle Alana Albuquerque Carneiro \\ Centro Universitário Metropolitano da Amazônia
}

RESUMO A preservação da biodiversidade marinha tornou-se um dos principais pontos a serem refletidos pela comunidade global atualmente. Com isso, de forma a mudar o cenário inexpressivo de cumprimento das metas da década passada, foram estabelecidas as metas de Aichi 2011-2020 para a biodiversidade, instituídas na $10^{\circ}$ reunião das partes - COP 10 , órgão diretor da Convenção sobre diversidade biológica (CDB). No ano limite para a implementação das metas 2011-2020, levanta-se o questionamento sobre o grau de efetividade alcançado pelo Governo Brasileiro e a importância da implementação das metas de proteção à biodiversidade marinha, sobretudo a meta 5, 6,11 e 14 que tratam, respectivamente, sobre a perda dos habitats marinhos nativos, a conservação das espécies marinhas ameaçadas, áreas marinhas protegidas e a gestão participativa dos serviços ecossistêmicos advindos do ecossistema marinho. Nessa perspectiva, o objetivo do presente artigo foi analisar o grau de eficiência e importância dados pelo Governo Brasileiro às metas de Aichi para 2020 referentes à biodiversidade marinha, por meio de documentos oficiais como o sexto relatório Nacional para a Convenção sobre Diversidade Biológica, publicado no website oficial da CDB em 29 de abril de 2020, apontando o fato de que o Brasil tem se preocupado mais com o cumprimento quantitativo das metas, as quais estão diretamente ligadas aos interesses políticos, em detrimento da qualidade da preservação e dos povos tradicionais que se utilizam de tais recursos.

Palavras-chave: Convenção sobre Diversidade Biológica (CDB); Metas de Aichi; Biodiversidade Marinha. 
Abstract The preservation of marine biodiversity has become one of the main points to be reflected by the global community today. Thus, in order to change the inexpressive scenario of meeting the goals of the past decade, the Aichi 2011-2020 targets for biodiversity were established at the 10th meeting of the parties - COP 10, the governing body of the Convention on Biological Diversity (CBD). In the final year for the implementation of the 20112020 goals, the question arises about the degree of effectiveness achieved by the Brazilian Government and the importance of implementing the goals for the protection of marine biodiversity, especially target 5, 6, 11 and 14, dealing respectively with the loss of native marine habitats, the conservation of endangered marine species, In this perspective, the objective of this article is to analyze the degree of efficiency and importance given by the Brazilian Government to the Aichi targets for 2020 regarding marine biodiversity, through official documents such as the sixth National report for the Convention on Biological Diversity, published on the official website of the CBD on April 29, 2020, pointing out the fact that Brazil has been more concerned with the quantitative fulfillment of the goals, which are directly linked to political interests, in detriment to the quality of preservation and the traditional peoples who use these resources.

Keywords: Convention on Biological Diversity (CBD); Aichi Goals; Marine BioDIVERSITY.

\section{INTRODUÇÃo}

Conforme publicado no Diário Oficial da União em 19 de maio de 2020, com extensão territorial total de $8.510 .295,914 \mathrm{~km}^{2}$, o Brasil é o quinto maior país do globo terrestre, ocupando quase a metade da América Latina. Já sua zona costeira é uma unidade territorial formada por mais de $8.500 \mathrm{~km}$, abrangendo dezessete estados e mais de 400 municípios, possuindo uma das maiores faixas costeiras do mundo, a qual se estende da foz do Rio Oiapoque, no Amapá, ao Chuí, no Rio Grande do Sul. Com sistemas ambientais costeiros altamente diversificados, o litoral brasileiro é composto por águas frias no Sul e Sudeste, e águas quentes no Norte e Nordeste, o que confere suporte a uma grande variedade de ecossistemas como manguezais, recifes de corais, dunas, restingas, praias arenosas, lagoas e estuários que abrigam inúmeras espécies de fauna e flora (MMA, 2020).

A partir do momento que a comunidade global despertou para a necessidade da preservação do meio ambiente como pressuposto para a própria conservação da vida, o Brasil se viu responsável por implantar, em seu território, 20 metas globais e nacionais de Aichi 20112020, instituídas durante a $10^{\circ}$ reunião das Partes - COP 10, órgão diretor da Convenção sobre Diversidade Biológica (CDB), cujo cumprimento deve se dar até o fim do presente ano. De todas as medidas de proteção, uma das mais fundamentais diz respeito à preservação da biodiversidade marinha que iniciou os prazos atuais com resultados inexpressivos, suscitando o seguinte questionamento: No ano limite para a efetivação das metas de Aichi 2011-2020, qual o grau de efetividade alcançado e a importância de serem cumpridas as metas de preservação da biodiversidade marinha?

Tais indagações justificam-se pois a sociedade brasileira assiste mais uma vez tais prazos escoarem-se sem que se possa vislumbrar avanços expressivos rumo ao cumprimento 
de tais metas, em contrapartida, o que se vê são interesses políticos colocados acima da preservação, desastres ambientais como o ocorrido na costa nordestina no ano de 2019 aliado à inércia do Governo Brasileiro na recuperação e sua negligência com povos tradicionais que se utilizam dos recursos marinhos para sobreviver, em clara contradição com os objetivos traçados pelas metas de Aichi 2011-2020, principalmente em relação ao modelo de gestão participativa na distribuição de serviços ecossistêmicos, tornando-se um importante e atual tema para reflexão.

Nessa perspectiva, o objetivo deste trabalho é investigar o tratamento dado à biodiversidade marinha pelo Governo Brasileiro na última década por meio de uma pesquisa bibliográfica e documental, principalmente em relação aos documentos públicos "Diálogos sobre Biodiversidade: construindo a estratégia brasileira para 2020 - Documento base da consulta pública", que estabelece a situação em que o país se encontrava no início do prazo para a implementação de tais metas e o sexto relatório Nacional para a Convenção sobre Diversidade Biológica, publicado em 29 de abril de 2020 pela CDB que apresenta o panorama atual das medidas adotadas pelo Governo Brasileiro em relação às metas de Aichi 2011-2020. Portanto, o trabalho segue a linha de pesquisa Direito, Meio Ambiente e Sustentabilidade.

Para tanto, será necessário perpassar pelo seguinte caminho: 1) Demonstrar a evolução histórica da noção protecionista dada ao meio ambiente ao longo dos anos, principalmente pela Constituição Federal, e o caminho percorrido até a incorporação das metas de Aichi em território nacional; 2) Definir o objetivo das metas de Aichi relacionadas especificamente à proteção da biodiversidade marinha e de que maneira o Brasil iniciou o prazo para o seu cumprimento; 3) Por fim, analisar criticamente os dados contidos no relatório nacional publicado no presente ano pela $\mathrm{CDB}$ e a atual realidade vivida pela biodiversidade marinha brasileira, culminando em uma reflexão a respeito da importância de se conservar tais ambientes para as presentes e futuras gerações.

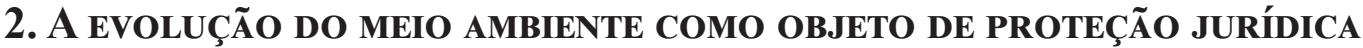

Cada vez mais, desastres ambientais têm se tornado notícia frequente nos diversos meios de comunicação existentes. Desmatamentos, enchentes, tráfico de animais e derramamento de óleo na costa brasileira têm despertado o mundo para importantes questões envolvendo a proteção do meio ambiente que, até então, mostravam-se esquecidas. Em meio a discussões ferrenhas entre ambientalistas e céticos a respeito da disponibilidade dos recursos naturais no território brasileiro, a única certeza é a de que nunca foi tão importante reafirmar o Direito ambiental como um direito fundamental, não só para as atuais, mas também para as futuras gerações.

A discussão envolvendo a relação de utilização de recursos naturais e proteção ambiental remontam às primeiras formas de organizações humanas no mediterrâneo, com a construção de fortificações para proteção do meio de habitação por povos nômades, até a formação de civilizações organizadas que começaram por estabelecer residência permanente próxima a locais abundantes em recursos naturais, sobretudo recursos hídricos, provocando modificações do seu estado natural de forma a garantir maior comodidade (TRENNPOHL, 2019, p. 25). 
À medida em que as civilizações humanas galgavam novos níveis de desenvolvimento, enfatiza Trennpohl (2019, p. 26), a ideia de proteção do meio em que viviam foi sendo deixada de lado em nome do "progresso" e avanço científico, sobretudo no fim do Séc. XVIII, quando se pôde observar uma crescente exploração e utilização dos recursos naturais.

Tal desenvolvimento tecnológico e o crescimento demográfico conferiram ao homem um domínio quase que ilimitado da natureza. Aliado a esse crescimento, surgiu uma ideia de inesgotabilidade dos recursos naturais, ideia que, equivocadamente, ainda é sustentada por muitos, contudo, não se deve esquecer que, pela sua própria composição e distribuição pela extensão da terra, diferentemente do que acreditam, esses recursos são limitados. O resultado de séculos de exploração baseado nesse achismo foi o surgimento de um dos mais importantes problemas a serem solucionados pelo homem: o da degradação ambiental.

Isso porque o desequilíbrio ambiental coloca em risco a própria existência do homem. Tal desequilíbrio gerou guerras por áreas mais prósperas, alterando o quadro histórico, com a supressão de culturas, a imposição de regras, a aniquilação de espécies e o massacre de populações (Trennepohl, 2019, p. 28). Assim, quando o ser humano entendeu a relevância desse assunto, surgiu a necessidade de se positivar o direito ambiental como um direito fundamental, como condição sine qua non para a efetivação dos demais direitos. A doutrina e jurisprudência brasileira vêm adotando esse posicionamento, como será demonstrado ao longo deste trabalho.

Para se fazer uma análise do grau de eficiência e importância das políticas públicas existentes para a conservação da biodiversidade marinha brasileira, objeto específico deste trabalho, em primeiro lugar, faz-se necessário traçar uma linha histórica das posturas e compromissos assumidos pelo Brasil nos últimos anos envolvendo proteção e conservação das biodiversidades, iniciando com o entendimento da Constituição Federal em relação ao meio ambiente, dando posteriormente enfoque à Convenção sobre Diversidade Biológica (CDB) e as metas de Aichi 2011-2020, já que se tratam de importantes acordos ambientais celebrados durante a Conferência das Nações Unidas sobre o meio ambiente e o desenvolvimento, em 1992, no Rio de Janeiro.

\section{A Constituição Federal de 1988: direito ambiental Como UM di- REITO DIFUSO}

Em atenção às constantes mudanças sociais e sua relação com o meio ambiente, o crescimento desordenado, o acelerado avanço tecnológico ligado à criação da chamada sociedade da informação, no século XXI, foi necessário a adoção de um posicionamento, para a tutela dos valores ambientais, que abandonasse uma ideia eurocêntrica em relação às ideias de propriedade e posse outrora estabelecidos, para conferir características próprias de transcendência ao direito ambiental.

Nem com características de um bem público e nem tampouco de um bem privado, o artigo 225 da Constituição Federal de 1988 consagrou um terceiro gênero de bem que pertence a todos, sob fundamento do que podemos chamar de direito difuso (TRENNEPOHL, 2019, p. 28). Assim dispõe o citado artigo: 
Art. 225 CF/88. Todos têm direito ao meio ambiente ecologicamente equilibrado, bem de uso comum do povo e essencial à sadia qualidade de vida, impondo-se ao poder público e à coletividade o dever de defendê-lo e preservá-lo para as presentes e futuras gerações (Brasil, 1988).

A partir do referido preceito Constitucional, pode-se entender que o meio ambiente, sendo um direito difuso, pertence à toda coletividade. Isso quer dizer que sua titularidade pertence a um grupo de pessoas indeterminadas, ligadas entre si por uma relação jurídica. Outrossim, trata-se de um direito transindividual e indivisível (FIORILO, 2018, p. 58). Tais características levam à interpretação de que qualquer pessoa humana, nessa condição, é titular do direito ao meio ambiente, e, portanto, legitimada a exercê-lo.

O Supremo Tribunal Federal, no ano de 2017, por ocasião do julgamento da Ação Direta de Inconstitucionalidade 4.066/DF, sob relatoria da Ministra Rosa Weber (STF TRIBUNAL PLENO - ADI N4.066, Relatora: ROSA WEBER, Data de publicação DJE 07/03/2018), corroborou tal entendimento, merecendo destaque pertinente ponto suscitado pelo Ministro Celso de Mello, ao proferir seu voto:

Todos sabemos que os preceitos inscritos no art. 225 da Carta Política traduzem, na concreção de seu alcance, a consagração constitucional, em nosso sistema de direito positivo, de uma das mais expressivas prerrogativas asseguradas às formações sociais contemporâneas. Essa prerrogativa, que se qualifica por seu caráter de metaindividualidade, consiste no reconhecimento de que todos têm direito ao meio ambiente ecologicamente equilibrado. Trata-se, consoante já o proclamou o Supremo Tribunal Federal (RTJ 158/205-206, Rel. Min. CELSO DE MELLO), com apoio em douta lição expendida por CELSO LAFER ("A reconstrução dos Direitos Humanos", p. 131/132, 1988, Companhia das Letras), de um típico direito de terceira geração (ou de novíssima dimensão), que assiste, de modo subjetivamente indeterminado, a todo o gênero humano, circunstância essa que justifica a especial obrigação - que incumbe ao Estado e à própria coletividade (PAULO AFFONSO LEME MACHADO, "Direito Ambiental Brasileiro", p. 121/123, item n. 3.1, 13ª ed., 2005, Malheiros) - de defendê-lo e de preservá-lo em benefício das presentes e futuras gerações, evitando-se, desse modo, que irrompam, no seio da comunhão social, os graves conflitos intergeneracionais marcados pelo desrespeito ao dever de solidariedade na proteção da integridade desse bem essencial de uso comum de todos quantos compõem o grupo social. (BRASIL, STF, 2017).

O artigo 23, incisos VI e VII da Constituição Federal, por sua vez, estabelecem a competência comum da União, Estados, Distrito Federal e Municípios para proteção do meio ambiente e combate à poluição em todas as suas formas, impondo-se também a responsabilidade pela preservação das florestas, fauna e flora (BRASIL, 1988).

Especificamente em relação à biodiversidade marinha e crimes cometidos contra ela, o artigo 225 da Constituição Federal confere, em seu parágrafo quarto, à zona costeira a condição de "patrimônio nacional" que não se confunde com o chamado "bem da União" (BRASIL, 1988), conforme restou decidido em outro julgado do STF, no Recurso Extraordinário 835.558/SP (STF - TRIBUNAL PLENO - RE No 835.558/SP, MINISTRO RELATOR: LUIZ FUX, Data de Publicação no DJE 08/08/2017), com repercussão geral re- 
conhecida, de forma que somente nesse último caso, a competência da Justiça Federal para processar e julgar o crime ambiental será atraída.

O que se infere do julgado retromencionado é que, havendo a incidência conjunta da transnacionalidade e a assunção de compromisso internacional de repressão ao cometimento de delito ambiental, a competência da Justiça Federal será atraída, por estar envolvido o interesse direto e específico da União.

Assim, ocorrendo casos de calamidade ambiental como, por exemplo, o caso do derramamento de óleo na zona costeira do Nordeste Brasileiro no anopassado, incontestável que se trata de bem da União, nos termos do art. 20 da Constituição, merecendo, portanto, tutela do Estado, eis que presentes o interesse direto e específico da União de forma a fazer incidir a responsabilização do Poder Executivo Federal por todas as medidas de resposta e mitigação aos danos ambientais provocados.

\section{A CONVENÇÃo SOBRE DIVERSIDADE BIOLÓGICA (CDB)}

O Brasil é detentor da maior e mais rica biodiversidade mundial e foi o primeiro país a assinar a Convenção de Diversidade Biológica, considerado um marco histórico para a proteção ao meio ambiente. Isso porque foi o primeiro instrumento a abordar à discussão, em âmbito internacional, a tutela do meio ambiente como um elemento fundamental para o desenvolvimento sustentável. Juntamente com a Agenda 21, a convenção de Diversidade Biológica é um dos principais tratados ambientais celebrados pelos países participantes durante a Conferência das Nações Unidas sobre o meio ambiente e o desenvolvimento, popularmente conhecida como Rio 92.

O período para assinaturas iniciou-se com o evento, no dia 5 de junho de 1992, e encerrou-se com ele no dia 14. Após esse período, do dia 15 de junho de 1992 a 4 de junho de 1993 esteve aberto para assinatura na sede das Organizações Unidas (ROMA, 2016). Ao total, 168 países tornaram-se signatários do acordo internacional, ressaltando sua relevância para a proteção das biodiversidades, termo que acabara de ser criado na própria Conferência.

Como todo acordo celebrado envolvendo uma multilateralidade de partes, a CDB precisava instrumentalizar normas e criar instituições que fossem capazes de regular as relações multilaterais e gerir os avanços das ações implementadas pelos países em cumprimento das obrigações assumidas. Em âmbito internacional, a CDB é implementada e monitorados os seus avanços pela Convenção das partes, criada pelo art. 23, formada pelos representantes dos países-membros assim também como observadores interessados de países não partes e organizações não governamentais. Suas reuniões ocorrem a cada dois anos e seu propósito é avaliar o progresso na implementação das metas, ajustá-las, estabelecerem protocolos e consequentemente a criação de novas metas para atingirem o objetivo da convenção. Até o momento foram realizadas quatorze sessões ordinárias da $\mathrm{COP}$, sendo que a primeira ocorreu em Nassau, Bahamas, em 1994, e a próxima estava inicialmente prevista para acontecer em Kunming, na China, em outubro de 2020, mas por conta da pandemia mundial da COVID-19, foi remarcada para maio de 2021 na mesma cidade.

Na Convenção das partes 10, ou COP 10, realizada em Nagoya, no Japão, as partes celebraram e assinaram o protocolo de Nagoya, estabelecendo as 20 metas de Aichi que tra- 
duziram a necessidade sentida, naquele momento, de firmarem compromissos ambientais no sentido de uma preservação global. As metas de Aichi serão tratadas especificamente mais à frente. $\mathrm{O}$ fato é que na $\mathrm{COP} 15$, as partes estabeleceram novas metas globais para a preservação da biodiversidade em substituição às 20 metas de Aishi estabelecidas na COP 10 , cujo prazo de validade expira no presente ano.

Dessa forma, pode-se dizer que os grandes objetivos da Convenção de Diversidade Biológica, previstos em seu art. $1^{\circ}$, são, respectivamente, a conservação da diversidade biológica, a utilização sustentável de seus componentes e a repartição justa, entre a população, dos frutos advindos da utilização dos recursos genéticos (ROMA, 2016). Assim, constata-se que, em relação a outros países signatários, o Brasil possui certo protagonismo, visto que possui um elevado nível de biodiversidade, tornando-se o mais importante responsável, em escalada global, em gerir, direta ou indiretamente, serviços ecossistêmicos.

Conforme o disposto no art. 36 do texto da Convenção, a CDB entrou em vigor no dia 29 de dezembro de 1993. O Brasil, como já mencionado, tornou-se o primeiro signatário do documento, em 5 de junho de 1992. Em 3 de fevereiro de 1994, a CDB foi ratificada pelo Congresso Nacional, por meio do Decreto Legislativo n. ${ }^{\circ} 2$ de 3 de fevereiro de 1994, tornando-se uma lei de biodiversidade.

Um dos principais pontos incorporados no texto da CDB, está o reconhecimento da soberania dos Estados para a utilização e disposição dos recursos naturais presentes em seu território, contudo, cediço que foi necessário impor alguns limites e restrições à essa utilização. Isso quer dizer que sendo signatário da CDB, o Brasil assumiu um compromisso mundial de preservar a sua biodiversidade e cumprir as metas estabelecidas sob pena de penalização internacional.

Antes que se estabeleçam as metas específicas que serão tratadas no presente trabalho, importante se faz o esclarecimento, com mais detalhes, de que formas a CDB impactou o Brasil por meio de uma rápida análise dos resultados relacionados à sua implementação em âmbito nacional.

\subsection{A Implementação da CDB no Brasil e o estabelecimento das metas nacionais de biodiversidade}

A implementação da CDB no Brasil envolveu a criação de regulamentos, normas legais e o estabelecimento de pontos prioritários de preservação por meio do envolvimento direto de instituições em conjunto com o Governo. Conforme já mencionado, a CDB iniciou sua história no Brasil por meio da aprovação do seu texto pelo Congresso Nacional, por meio do Decreto n. ${ }^{\circ} 2$, de 3 de fevereiro de 1994, e posterior ratificação na sede das Organizações Unidas, em Nova Iorque. Assim, passando a vigorar em todo o território nacional em 29 de maio de 1994, quando o Presidente Itamar Franco determinou que fosse executada integralmente, conforme redação original. Cumpre dizer que foi promulgada pelo Decreto $\mathrm{n}^{\circ} 2.519$, de 16 de março de 1998.

Por sua vez, o art. $6^{\circ}$ da CDB ressalta que a obrigação das Partes em estabelecerem estratégias, planos ou programas para conservação e a utilização sustentável da biodiversidade, adaptando-as, se preciso for, a fim de que se encaixem nos objetivos da Convenção. O principal mecanismo de implementação desses objetivos, em âmbito nacional e interna- 
cional, foi a elaboração de uma Estratégia Nacional de Biodiversidade e planos de ação a ela relacionados.

Assim, no ano de 1990, o Brasil iniciou o desenvolvimento de uma estratégia nacional de biodiversidade, guiando-se, inicialmente, por seis elementos, começando pela realização de estudos estratégicos para o futuro estabelecimento da Política Nacional de Biodiversidade, passando à definição de áreas prioritárias para sua conservação, afirmadas pela Portaria MMA n'126/2004 (ROMA, 2016, p. 226).

Depois disso, houve o estabelecimento de um marco legal, ou seja, da Política nacional da biodiversidade por meio do Decreto n. ${ }^{\circ} 4.339 / 2002$, a criação do Programa Nacional de Diversidade Biológica (Pronabio) por meio do Decreto n. ${ }^{\circ}$ 1.354/94 e também a implementação da Comissão Nacional da Biodiversidade (Conabio) pelo Decreto $n^{\circ} 4.703 / 2003$. Por fim, a implementação da Política Nacional da Biodiversidade que estabeleceu as diretrizes e prioridades do plano de ação da Política Nacional da Biodiversidade e sua implementação. Posteriormente, isso foi corroborado pela definição das metas nacionais de biodiversidade e ações de implementação correlatas (ROMA, 2016).

Durante a realização da COP 6 da CDB, realizada em Haia, Holanda em 2002, pormeio da Decisão VI/26 foi estabelecido que o propósito do plano estratégico da CDB seria reduzir expressivamente a perda da biodiversidade até 2010. O conjunto de metas estabelecidas para esse propósito ficaram conhecidas como "a meta de 2010". Mais tarde, por ocasião da realização da COP 8, sediada por Curitiba-Paraná, as metas foram melhor estruturadas, resultando em 21 metas globais. Em atenção a isso, o Brasil consagrou 51 metas nacionais de biodiversidade a serem implementadas até 2010, adotadas pela resolução Conabio n³/2006 (ROMA, 2016). Nem precisa se dizer que foi um fracasso, com resultados bastante inexpressivos em relação à proteção da biodiversidade.

Dessa maneira, de um sentimento que havia mais a se fazer para não repetir o fracasso das metas de 2010, durante a COP 10, realizada em Nagoya, no Japão, as partes adotaram metas revisadas de biodiversidade, adotando o novo Plano Estratégico de 2011-2020. Esse plano constitui-se de vinte metas, batizadas como metas de Biodiversidade de Aichi, subdivididas em cinco objetivos estratégicos que envolvem o tratamento de causas fundamentais de perda da biodiversidade, a redução das pressões diretas sobre ela de forma a incentivar o desenvolvimento sustentável, melhorá-la no sentido de proteção ao ecossistema, espécies e diversidade genética, democratizar a distribuição dos benefícios da biodiversidade e serviços ecossistêmicos e o aumento da implementação por meio da participação popular, do engajamento e da capacitação.

Assim, segundo Roma (2016), em cumprimento do estabelecido pela Convenção, o Brasil iniciou em 2011 o processo de revisão das estratégias antigas por meio do programa Diálogos sobre biodiversidade: construindo a estratégia brasileira para 2020. Tal iniciativa teve como resultado 12 eventos nacionais que contaram com a participação dos mais variados setores sociais, principalmente da iniciativa privada, e, assim, foram estabelecidas as metas nacionais de biodiversidade 2011-2020, adotadas por meio da Resolução CONA$\mathrm{BIO} n^{\circ} 6$ de 3 de setembro de 2013. Posto isso, é necessário fazer uma análise das metas correlacionadas ao objeto específico do presente trabalho, quais sejam, as metas brasileiras relacionadas à preservação da biodiversidade marinha. 


\section{2. As metas globais e nacionais para a preservação da biodiversidade Marinha 2011-2020}

Como supracitado, do sentimento de fracasso em relação ao cumprimento das metas estabelecidas pelas partes até o ano de 2010, houve o aperfeiçoamento das metas anteriormente estabelecidas por meio da aprovação do novo plano estratégico das Metas de Aichi 2011-2020, ocasião em que foram definidos cinco objetivos estratégicos e 20 metas globais a serem implementadas pelos países participantes até o final do presente ano.

Dessa forma, o governo brasileiro, por meio do Ministério do Meio Ambiente, adotando um posicionamento participativo a fim de adequar as metas estabelecidas à realidade nacional, em 2011, promoveu cinco grandes reuniões para consultas presenciais junto aos mais diversificados setores sociais que, como resultado, geraram vinte e cinco documentos contendo as metas nacionais de biodiversidade. Posteriormente, todas as propostas contidas nesses documentos foram reunidas em um único documento, intitulado "Diálogos sobre Biodiversidade: construindo a estratégia brasileira para 2020 - Documento base da consulta pública".

Por meio da Resolução $n^{\circ}$ 6, de 3 de setembro de 2013 da Conabio, foram estabelecidas, definitivamente, as Metas Nacionais de Biodiversidade para 2020, tomando por base as metas globais de Aichi estabelecidas na COP 10. Por meio da mesma resolução, foram estabelecidas também diretrizes para a internalização e cumprimento no território brasileiro.

Importante salientar que o planejamento e desenvolvimento das metas nacionais aqui mencionadas, fizeram-se em razão do cumprimento da decisão V/26 da COP 6, a qual os países participantes solicitaram a definição de metas nacionais para a redução dos índices de perda de biodiversidade alinhadas ao objetivo da Convenção sobre Diversidade Biológica (CDB). Assim como as metas globais, as metas nacionais de biodiversidade 2011-2020 adotaram a mesma estrutura de cinco objetivos estratégicos e 20 metas a serem efetivadas em território nacional até 2020, as quais serão comparadas abaixo, limitando-se àquelas relacionadas à preservação da biodiversidade marinha, subdivididas em seus objetivos estratégicos respectivos. Cumpre dizer que em relação aos objetivos estratégicos $\mathrm{A}$ e $\mathrm{E}$ não serão analisadas nenhuma de suas metas e, portanto, não serão mencionados.

Objetivo estratégico B: Reduzir as pressões diretas sobre a biodiversidade e promover o uso sustentável. 
Tabela 1: Comparativo entre as metas globais e nacionais 5 e 6.

\begin{tabular}{|l|l|}
\hline $\begin{array}{l}\text { Meta global 5 - Até 2020, a taxa de perda } \\
\text { de todos os habitats nativos, inclusive flores- } \\
\text { tas, terá sido reduzida em pelo menos metade }\end{array}$ & $\begin{array}{l}\text { Meta nacional 5 - Até 2020 a taxa de perda } \\
\text { de ambientes naturais será reduzida em pelo } \\
\text { menos } 50 \% \text { (em relação às taxas de 2009) }\end{array}$ \\
$\begin{array}{l}\text { zero, e a degradação e fragmentação terão } \\
\text { sido reduzidas significativamente. }\end{array}$ & $\begin{array}{l}\text { zero, e a degradação e fragmentação terão } \\
\text { sido reduzidas significativamente em todos } \\
\text { os biomas. }\end{array}$ \\
\hline $\begin{array}{l}\text { Meta global 6-Até 2020, o manejo e captura } \\
\text { de quaisquer estoques de peixes, inver- } \\
\text { tebrados e plantas aquáticas serão sustentá- } \\
\text { veis, legais e }\end{array}$ & $\begin{array}{l}\text { Meta nacional 6 - Até 2020, o manejo e } \\
\text { captura de quaisquer estoques de organismos } \\
\text { aquáticos serão sustentáveis, legais e feitos } \\
\text { com }\end{array}$ \\
\hline
\end{tabular}

feitos com aplicação de abordagens ecossistêmicas, de modo a evitar a sobrexploração, colocar em prática planos e medidas de recuperação para espécies exauridas, fazer com que a pesca não tenha impactos adversos significativos sobre espécies ameaçadas e ecossistemas vulneráveis, e fazer com que os impactos da pesca sobre estoques, espécies e ecossistemas permaneçam dentro de limites ecológicos seguros. aplicação de abordagens ecossistêmicas, de modo a evitar a sobrexploração, colocar em prática planos e medidas de recuperação para espécies exauridas, fazer com que a pesca não tenha impactos adversos significativos sobre espécies ameaçadas e ecossistemas vulneráveis, e fazer com que os impactos da pesca sobre estoques, espécies e ecossistemas permaneçam dentro de limites ecológicos seguros, quando estabelecidos cientificamente.

Objetivo estratégico C: Melhorar a situação da biodiversidade protegendo ecossistemas, espécies e diversidades genéticas.

Tabela 2: Comparativo ente a meta global e nacional 11.

Meta global 11 - Até 2020, pelo menos 17\% de áreas terrestres e de águas continentais e $10 \%$ de áreas marinhas e costeiras, especialmente áreas de especial importância para a biodiversidade e serviços ecossistêmicos terão sido conservados por meio de sistemas de áreas protegidas, geridas de maneira efetiva e equitativa, ecologicamente representativas e satisfatoriamente interligadas e por outras medidas espaciais de conservação, e integradas em paisagens terrestres e marinhas mais amplas.
Meta nacional 11 - Até 2020, serão conservadas, por meio de unidades de conservação previstas na Lei do SNUC e outras categorias de áreas oficialmente protegidas, como APPs, reservas legais e terras indígenas com vegetação nativa, pelo menos 30\% da Amazônia, $17 \%$ de cada um dos demais biomas terrestres e $10 \%$ de áreas marinhas e costeiras, principalmente áreas de especial importância para a biodiversidade e serviços ecossistêmicos, assegurada e respeitada a demarcação, regularização e a gestão efetiva e equitativa, visando garantir a interligação, integração e representação ecológica em paisagens terrestres e marinhas mais amplas.

Objetivo estratégico D: Aumentar os benefícios de biodiversidade e serviços ecossistêmicos para todos. 
Tabela 3: Comparativo entre a meta global e nacional 14.

\begin{tabular}{l|l|} 
Meta global 14 - Até 2020, ecossistemas & Meta nacional 14 - Até 2020, ecossistemas \\
provedores de serviços essenciais, inclusive & provedores de serviços essenciais, inclusive \\
serviços relativos à água, que contribuem à & serviços relativos à água e que contribuem à \\
saúde, meios de vida e bem-estar, terão sido & saúde, meios de vida e bem-estar, terão sido \\
restaurados e preservados, levando em conta & restaurados e preservados, levando em conta \\
as necessidades das mulheres, comunidades & as necessidades das mulheres, povos e comu- \\
indígenas e locais, e de pobres e vulneráveis. & $\begin{array}{l}\text { nidades tradicionais, povos indígenas e comu- } \\
\text { nidades locais, e de pobres e vulneráveis. }\end{array}$ \\
\hline
\end{tabular}

Como pode ser facilmente analisado, as metas nacionais guardam expressivas semelhanças com as metas globalmente estabelecidas, demonstrando mais uma vez que o Brasil, por ocasião da incorporação de tais metas, comprometeu-se seriamente em cumpri-las até o final do presente ano.

Em 2011, como parte do projeto "Diálogos sobre Biodiversidade: Construindo a estratégia brasileira para 2020", O Ministério do Meio Ambiente (MMA), em parceria com a União Internacional para a Conservação da Natureza (UICN), o WWF-Brasil e o Instituto de Pesquisas Ecológicas (IPÊ), financiados pelo DEFRA, por meio da Embaixada Britânica no Brasil, lançaram o documento público chamado "Metas de Aichi: Situação atual no Brasil" cujo objetivo era apresentar a situação do Brasil naquele momento em relação às Metas traçadas durante a COP 10 da CDB e também apresentar propostas e recomendações para o devido cumprimento. Assim, para que se verifique a efetividade das medidas adotadas pelo Brasil para o cumprimento das metas em 2020, faz-se necessário, primeiramente, estabelecer-se como o País se encontrava no período inicial das metas, ou seja, em 2011, a partir da análise feita pelo referido documento público.

Cumpre dizer que a proposta do documento era, em um primeiro momento, analisar a meta em si mesma, para depois estabelecer possíveis indicadores de cumprimento em relação às anteriormente estabelecidas para o ano de 2010 e, em seguida, apontar recomendações ao Governo Brasileiro que o ajudassem a redirecionar suas ações quando do estabelecimento das metas 2011-2020.

Iniciando pela meta de número cinco, pertencente ao objetivo estratégico $\mathrm{B}$, pela leitura da referida meta, pode-se perceber que ela se preocupa com a transformação dos habitats nativos em ambientes de uso, o que é chamado de uma forma de apropriação do território brasileiro pelo documento público (MMA, 2011, p. 21). Vários modos de exploração são retratados na análise da referida meta, tais como a mineração, urbanização, agricultura, pecuária e a própria aquicultura.

Interessante notar na análise feita de que esse ciclo de exploração acaba provocando uma sustentabilidade determinada por fatores econômicos (MMA, 2011, p. 22) que acabam por se estabelecerem em locais específicos, dependentes de uma série de fatores que facilitam a ocupação cuja causa básica, segundo o documento encabeçado pelo Ministério do Meio Ambiente (MMA, 2011, p. 22), é, entre outras citadas no documento, "a incapacidade dos usuários da terra de transformar as oportunidades potenciais dos habitats nativos em ganhos econômicos reais". 
A análise feita dessa meta específica demonstrou como indicador de cumprimento o desmatamento. Assim, ao apresentarem os percentuais de desmatamento para aquele ano, reconheceram a importância da manutenção das metas de combate ao desmatamento como prevenção da perda da biodiversidade para o ano de 2020. Contudo, cumpre aqui frisar que a meta, desde a sua origem, mostrou-se frágil quanto a incorporação dos habitats aquáticos e marinhos, cuja lacuna deveria ser preenchida pelo estabelecimento das metas para 2020 (MMA, 2011, p. 23). Isso quer dizer que a proteção da biodiversidade marinha não foi incluída no projeto de preservação, o que se mostra, no mínimo, preocupante. Passando à meta seis que trata da pesca sustentável, ainda incluída no objetivo estratégico $\mathrm{B}$, o indicativo apontado que demonstraria o seu cumprimento seria a redução do esforço de pesca por limitação governamental (MMA, 2011, p. 25). Uma análise importante feita em relação a essa meta foi de que quando se fala em uma alta produção de peixes, dentro de uma ideia de desenvolvimento, na verdade pode se tratar de uma alta extração, sem dar atenção devida à capacidade reprodutiva da espécie, o que poderá causar problemas de sustentabilidade.

Tal meta foi considerada um tanto desafiadora, tanto para o ano de 2010, quanto para o ano de 2020. Não é difícil acreditar que o Brasil iniciou o período de cumprimento para as metas de 2020 com resultados quase inexpressivos quanto a essa meta, pois o histórico de exploração pesqueira brasileira aumenta a cada ano, sem levar em consideração o desrespeito ao período de defeso e a pesca predatória.

Uma das recomendações para mudar esse quadro consistia na substituição da pesca extrativa pela aquicultura, mais que isso, e esse é o ponto que se pretende destacar, está o estabelecimento de áreas protegidas marinhas para manter e recuperar os estoques pesqueiros (MMA, 2011. p. 27). Até o ano de 2010, o Brasil criou um número inexpressivo de áreas protegidas onde a pesca é proibida, estabelecendo aqui uma importante questão que deveria vir a ser enfrentada pelo estabelecimento das metas para 2020.

O objetivo estratégico C, por meio da meta 11, apresenta um dos mais relevantes pontos a serem analisados pelo presente trabalho, no que diz respeito a áreas conservadas por meio de sistemas de áreas protegidas. No ano de 2009, um ano antes da data limite para o cumprimento das metas de 2010,o Brasil respondia por cerca de 75\% das áreas protegidas criadas no mundo desde 2003 (MMA, 2011, p. 39).

A análise dessa meta ressaltou ricos dados sobre a porcentagem existente de áreas de preservação permanente (APPs) e as reservas legais (RLs) e as estratégias de monitoramento e integração adotadas pelo Brasil por meio do sistema SNUC. Contudo, limitou-se a estabelecer os dados do Pantanal, Amazônia, Cerrado, Mata Atlântica, Caatinga e Pampa, sem fazer menção específica às áreas de preservação marinhas, embora esteja expressamente na meta onze a preservação em, pelo menos, $10 \%$ de áreas marinhas e costeiras. Segundo Silva (2019, p. 9) a "disparidade existente entre os níveis de proteção de ecossistemas terrestres e os ecossistemas costeiros e marinhos reforçou a necessidade da adoção do objetivo".

A ideia por trás da meta 11 e o ponto central de sua discussão residia no fato de que as áreas protegidas são comprovadamente eficientes na preservação de habitats naturais e de espécies e fundamentais para os serviços ecossistêmicos, se monitoradas e gerenciadas (SILVA, 2019, p. 9). Outro importante ponto em relação a essa meta está no tratamento adotado pela COP em relação às áreas de proteção, segundo Silva (2019, p. 10):

]Portanto, por um lado, os Estados, cientes da dificuldade de implementar o 
objetivo de se proteger pelo menos $10 \%$ das áreas marinhas até o ano de 2012 , decidiram estender o prazo até 2020. Por outro lado, a meta 11 de Aichi demonstra uma evolução no posicionamento da COP em direção a uma afirmação mais enérgica do papel a ser desempenhado pelas áreas protegidas e pelas redes de áreas protegidas, isso porque em 2006 - apenas quatro anos antes da adoção das Metas de Aichi - a COP-8 considerou as áreas protegidas e as redes de áreas protegidas apenas uma das ferramentas para proteger a biodiversidade. Em 2010, a COP passou a considerá-las como instrumento principal na proteção da biodiversidade marinha. Além disso, a COP passou a reconhecer que as AMPs podem ser utilizadas não somente para proteger a biodiversidade, mas também para salvaguardar serviços ecossistêmicos. (SILVA, 2019, p. 10).

Por fim, o objetivo estratégico D diz respeito aos benefícios trazidos pela biodiversidade, por meio de serviços ecossistêmicos que devem ser direcionados a todos. A meta 14 especificamente visa implementar, até 2020, ecossistemas provedores de serviços essenciais que podem ser considerados aqueles relativos à água, por meio de sua restauração e preservação, de modo a assegurar saúde, meio de vida e bem-estar, sem olvidar as necessidades de mulheres, indígenas, pobres e vulneráveis.

Por envolver interesses de grupos considerados vulneráveis, a meta 14 se apresenta como uma das mais importantes a serem cumpridas, justamente porque guarda em si uma noção de equidade na distribuição dos frutos advindos de serviços ecossistêmicos. Além disso, é possível fazer uma extensão dessa meta a todas as outras, uma vez que para se ter qualquer avanço a nível de preservação da biodiversidade, necessário se faz a inclusão e o incentivo à participação multisetorial, principalmente dos grupos que dependem de tais recursos para sobreviver, a exemplo dos pescadores e indígenas.

O documento ora analisado apresenta um amplo rol exemplificativo do que seriam tais serviços ecossistêmicos fornecidos pela biodiversidade, dos quais destacam-se a conservação dos recursos hídricos para consumo humano e animal, ligados à proteção dos rios, lagos e reservatórios contra acidentes de qualquer natureza, mantendo sua qualidade; também a própria vivência junto à natureza por meio de atividades educacionais, recreacionais, turísticas e espirituais e o provimento de base natural para o desenvolvimento de pequenos e grandes negócios, principalmente ligados à pesca (MMA, 2011, p. 52).

A análise de tal meta aliada ao desejo da multiplicação de seus benefícios e o desenvolvimento sustentável suscitou, à época, principalmente no que tocava à quantificação das áreas de preservação permanente, importante ponto a ser discutido na revisão do Código Florestal que era discutido pelo Congresso naquele momento (MMA, 2011, p. 53). Por meio do chamado estudo de SPAROVEK et al.(2011), mapeando a extensão total das APPs existentes, estendidas por um total de 103 milhões de hectares, constatou um déficit de $43 \%$ de suas áreas, equivalentes à 44 milhões de hectares (MMA, 2011, p. 53).

Embora existam metas relacionadas, percebe-se, pela análise das metas e do próprio tratamento dado a elas até aquele momento pelo Governo Brasileiro, que as metas para a Conservação da biodiversidade Marinha e dos recursos hídricos se mostravam insuficientes e frágeis, principalmente em relação aos serviços ecossistêmicos que se poderiam extrair delas.

Desse modo, os resultados inexpressivos de cumprimento das metas anteriores fizeram o Brasil entrar no início do prazo para o cumprimento das novas metas para a proteção 
das Biodiversidades 2011-2020 com resultados ainda mais inexpressivos em relação à proteção da Biodiversidade Marinha, como dito anteriormente, uma vez que nunca constituíram uma frente prioritária de preservação, ainda que fosse uma das fontes essenciais para a preservação da vida humana.

Sob a responsabilidade de mudar esse quadro, o Brasil adotou ambiciosas medidas para melhorar os baixos índices de preservação marinha obtidos até então, comprometendo-se a entregar à comunidade brasileira e global resultados mais amplos em relação ao que foi outrora estabelecido. Dessa forma, cumpre fazer uma análise dos resultados atuais obtidos pelo Brasil em relação às metas de preservação da biodiversidade marinha, tendo em vista que se encontra no ano limite para a sua implementação.

\section{Cenário atual do Brasil em relação ho CUMPrimento das metas de PROTEÇÃO DA BIODIVERSIDADE 2011-2020}

Uma das principais formas de monitoramento do avanço da implementação das metas se dá por meio do documento Global Biodiversity Outlook(GBO), no qual a situação mundial em relação ao cumprimento das metas estabelecidas é apresentada, constituindo a principal publicação da Convenção sobre Diversidade Biológica.

Além disso, outra importante fonte de informação contida na página da Convenção mantida pela CDB em relação aos avanços obtidos está nos relatórios periodicamente enviados pelos países partes, documentos em que são resumidos os dados recentes sobre a situação da biodiversidade naquele país e os indicativos de cumprimento das metas globais e internacionais. Dessa forma, cumpre analisar o último relatório enviado pelo Governo Brasileiro, cuja publicação pela CDB data de 29 de abril de 2020.

Considerando o disposto na Lei Complementar $n^{\circ}$ 140, de 8 de dezembro de 2011 que regula o Art. 23 da Constituição Federal, a responsabilidade pelo cumprimento das metas e implementação do plano de ação são distribuídas entre os entes federados, dos quais o Governo Federal responde por 40,8\%, os Governos Estaduais por 37,4\%, a sociedade civil por $13,7 \%$, o setor privado por $5,2 \%$, a academia por $2,8 \%$ e os municípios por $0,1 \%$ das ações (BRASIL, 2020, p. 21), importante se fazer uma análise das metas propriamente ditas, cujo objetivo não reside apenas em seu cumprimento frio, mas se as ações adotadas para esse cumprimento estão alinhadas com o super objetivo da Convenção da Diversidade Biológica: o Desenvolvimento Sustentável.

Além de destacar elementos qualitativos presentes nos dados fornecidos pelo Governo Brasileiro no sexto relatório Nacional para a Convenção sobre Diversidade Biológica, necessária se faz uma reflexão a respeito da importância da participação popular no cumprimento das metas, sobretudo das populações tradicionais e aquelas que dependem desses recursos, por meio de um comparativo entre os dados contidos no relatório e a realidade vivenciada pelo Brasil nos últimos anos.

\subsection{A perda de habitats nativos e a análise da meta 5}

Quando feita uma rápida apresentação da quinta meta para a biodiversidade, foi analisado que embora aborde elementos claros quanto a outros biomas, foi omissa quanto ao 
tratamento das zonas costeiras e marinhas que abrigam cerca de $1 / 4$ da população brasileira, percorrendo 463 cidades em 17 estados (WWF, sem data). Embora a recomendação dos envolvidos na produção do Documento Público produzido em 2011 seja no sentido de dar maior atenção à perda dos habitats nativos contidos nessas zonas especificamente, tem-se que no ano limite para a implementação de tal meta, o tratamento dado ainda é insuficiente.

Diante desse preocupante cenário, importantes questões podem ser suscitadas em relação à preservação das zonas costeiras e marinhas, compostas por 3 mil km de recifes de corais e $12 \%$ dos manguezais do mundo (WWF, sem data), como a importância dada pelo Governo e Sociedade Brasileira aessas áreas, a perda da capacidade de recuperação desses habitats, a sobrexploração, entre outras importantes discussões.

Entrevistada, a coordenadora do Programa Marinho e Mata Atlântica do WWF-Brasil, Anna Carolina Lobo relata que "a baixa conservação do mar e da costa brasileira se agrava com a falta de conhecimento sobre o universo marinho", e ainda ressalta que "A população e o governo de uma forma geral consideram que preservar os oceanos é menos urgente do que as florestas (...). Para se ter ideia, $54,7 \%$ de todo o oxigênio da Terra é produzido nos oceanos por algas marinhas" (WWF. Sem data).

Isso ainda se torna mais nítido quando analisado o sexto relatório Nacional para a Convenção sobre Diversidade Biológica, disponível no website da CDB (publicado em 29 de abril de 2020), cujo alvo descrito para a meta, contendo seis componentes, limita-se a quantificar reduções de taxas de perda de habitats nativos em 50\% apenas na Amazônia e Cerrado, apresentando a genérica menção de "redução significativa da degradação e fragmentação nos outros biomas" (BRASIL, 2020, p.7). A referida meta nacional conta com 46 ações no plano de ação do NBSAP (National Biodiversity Strategy and Action Plans), ou EPANB, que tratam da estratégia e plano de ação nacional para a biodiversidade (MMA, sem data).

Outro importante dado contido no relatório é o de que, em 2014, 9\% das espécies de peixes e invertebrados aquáticos encontram-se ameaçadas de extinção e o principal risco à perpetuação de suas espécies e dos seus habitats nativos é a atividade pesqueira. Entretanto, faltam dados estatísticos quanto à atividade pesqueira na última década, o que impede a análise da exploração que esses habitats vêm sofrendo em todo o território nacional (BRASIL, 2020, p. 175). Além disso, a poluição da água por meio do tráfego marinho, colisões de embarcações, turismo descontrolado e o desenvolvimento urbano costeiro se apresentam como a segunda maior causa de ameaça a esses habitats (BRASIL, 2020, p. 176).

Pode-se pensar que embora insuficiente os mecanismos de proteção quanto a esta meta específica, tal insuficiência pode ser superada pela previsão expressa da proteção à zona costeira e marinha contida em outras metas. Contudo, não é difícil perceber que tratam de metas distintas, com objetivos distintos. Assim, embora seja de extrema importância a preservação desses habitats, tem-se que o Brasil não alcançou níveis satisfatórios no cumprimento da preservação dos habitats nativos marinhos.

\subsection{A conservação de espécies marinhas ameaçadas e a análise da Meta 6}

Segundo o sexto relatório nacional para a Convenção sobre Diversidade Biológica (2020, p. 39), a avaliação do progresso da sexta meta nacional é feita de acordo com "três indicadores que medem a evolução da cobertura das áreas protegidas nas áreas marinhas, 
investimento em programas de pesca sustentável e avaliação do número de planos de recuperação para espécies aquáticas ameaçadas".

Como um todo voltado à recuperação de espécies marinhas ameaçadas, em relação a áreas marinhas, em 2018, o Brasil vivenciou uma expansão das áreas marinhas protegidas, estimando-se um aumento de 1,5\% para 26,34\%. Embora represente um importante aumento, os desafios para o avanço dessa meta estão na dificuldade de conciliar a implementação do SISNUC com as áreas marinhas consideradas relevantes para a recuperação de espécies marinhas ameaçadas que encontram entrave no setor produtivo. Além disso, falta o apoio social e governamental para a criação e a gestão de novas áreas protegidas (BRASIL, 2020, p. 40).

Não somente na criação e gestão de tais áreas, mas também na execução orçamentária de programas de preservação e ações do governo federal voltados à pesca. Segundo o relatório nacional, nos Planos Plurianuais de 2005 e 2015, ações voltadas às atividades pesqueiras somaram R \$ 867 milhões. Contudo, a partir de 2011 se observou uma decrescente execução orçamentária, chegando ao seu nível mais baixo em 2015, quando o Ministério da Pesca e Aquicultura foi extinto, contando somente com R\$ 11,4 milhões (BRASIL, 2020, p. 40).

Em relação aos planos de recuperação de espécies, em específico, 47 espécies foram consideradas prioritárias para a elaboração de planos de recuperação, das quais 23 se enquadram em nove planos de ação oficiais. Além disso, foi previsto que em 2019 entrariam na contagem mais 13 novos planos de recuperação supervisionados pelo Ministério do Meio Ambiente, o que não se efetivou até o presente momento. Ao final da avaliação nacional dessa meta, ainda, o Governo Brasileiro admite que alterações na gestão de pesca podem adiar a definição desses novos regulamentos (BRASIL, 2020, p. 40), evidenciando mais uma vez a sua ineficiência de desenvolver um sistema de pesca sustentável de forma a preservar habitats nativos e espécies marinhas ameaçadas.

Isso é preocupante se levado em consideração que a lista Nacional de Espécies da Fauna Ameaçada Brasileira de 2014, a mais atual, avaliou o risco de extinção de 5.149 peixes e invertebrados aquáticos, indicando que 475 espécies foram consideradas ameaçadas, das quais 99 são peixes marinhos, 310 peixes de interior e 66 invertebrados aquáticos (BRASIL, 2020, p. 86). O problema da sobrepesca fica ainda mais nítido quando consideramos que $90 \%$ dessas espécies marinhas a tem como principal causa de ameaça de extinção. Ao se questionar o porquê do Brasil não conseguir desenvolver um plano eficiente de pesca sustentável, pode-se indicar como uma das causas o conflito existente entre usuários dessa atividade, sobretudo pescadores artesanais e comerciais. A pressão causada pela grande pesca comercial desde 1960, fez com que comunidades fechassem lagos e proibissem a entrada de barcos pesqueiros de forma a evitar a sobrexploração, o que acabou ensejando a criação de "acordos de pesca", reconhecidos legalmente pelo IBAMA por meio da Instrução Normativa ${ }^{\circ} 29$, de 31 de dezembro de 2002.

Embora possam ser importantes instrumentos para preservação dessas espécies aliados às crescentes iniciativas envolvendo planos de manejo, ainda encontram entrave na fraca base organizacional, ausência de mecanismos que representem os interesses de todos os atores, de forma que tais acordos tenham força, sem correr o risco de não se reconhecer sua legitimidade, o que vem ocorrendo. Tais medidas podem mudar o quadro de ineficiência 
que o Brasil possui no cumprimento de tal meta. Assim, é necessário se fazer a análise da meta 11 que trata das áreas marinhas protegidas, onde parte desses indivíduos atuam.

\subsection{As áreas marinhas protegidas e a análise da Meta 11}

O sexto relatório Nacional para a Convenção sobre Diversidade Biológica deixa claro que o objetivo nacional para a referida meta está na implantação e expansão do sistema Nacional de Áreas Protegidas (BRASIL, 2020, p. 12) e conta com 118 ações no plano do NBSAP por meio da integração e registro das áreas protegidas no cadastro nacional, planos de manejo, avaliação da eficácia dessa proteção e apoio a sistemas de integração, tais como o sistema de mosaicos (BRASIL, 2020, p. 13). Embora a justificativa nacional seja clara que a meta em comento é composta de elementos quantitativos e qualitativos, por meio da conservação de $10 \%$ de áreas marinhas e costeiras por intermédio de áreas protegidas previstas na Lei do SNUC (BRASIL, 2020, p. 12), na prática tem se mostrado mais quantitativa que qualitativa.

Em um panorama global, em 2010, quando as metas de Aichi foramfixadas, somente $1,17 \%$ da cobertura marinha global estava protegida, segundo Silva (2019, p. 44) em seu artigo intitulado "A meta 11 de Aichi e as áreas marinhas protegidas em grande escala: proteção ambiental ou oportunismo político" publicado pela UniCEUB, apontando que "segundo os dados do World Database on Protected Areas (WDPA), em outubro de 2019, $28.189 .691 \mathrm{~km}^{2}$ (ou $8 \%$ da cobertura global oceânica)" passaram a ser protegidas em resultado do estabelecimento da $11^{\circ}$ meta.

No caso do Brasil, até o final de 2017, todos os biomas brasileiros, excetuando-se a Amazônia, estavam longe do alcance da meta. Dessa forma, no início de 2018, com a criação de Unidades de Conservação marinhas, o Governo Brasileiro dobrou a quantidade de áreas costeiro-marinhas protegidas, saltando de $1,51 \%$ para $26,36 \%$ com a criação das UCs marinhas dos arquipélagos de São Paulo e São Pedro e das Ilhas Trindade e Martim Vaz (BRASIL, 2020, p. 54), contudo, não levou em consideração as áreas prioritárias de preservação da biodiversidade (BPBES, 2019, p. 58).

Tal análise é corroborada por Silva (2019, p. 47) ressaltando que, embora considere áreas protegidas marinhas em um aspecto internacional, constata que o estabelecimento das áreas protegidas marinhas dificilmente levam em consideração "a representatividade ecológica e o gerenciamento efetivo e equitativo", transformando-se em uma corrida para estabelecer áreas protegidas em grandes áreas em detrimento da constituição de pequenas áreas protegidas por falta de recursos, ainda que se mostrem mais efetivas no sentido de proteção.

Isso significa que o fator político pareceu permear o processo de criação dessas áreas de proteção marinha. Tomando como exemplo a criação das áreas de proteção marinha em Trindade e Martin Vaz, considerando que os dois anos que antecederam a criação foram permeados por notícias ruins envolvendo o meio ambiente, segundo Silva (2019, p. 50), à época, o governo Temer, depois que "todos os prazos foram encurtados ao máximo para que o então presidente pudesse anunciar, em um evento internacional $-8^{\circ}$ Fórum Mundial da Água, realizado em Brasília - o estabelecimento das áreas protegidas". De fato, um verdadeiro oportunismo político.

Assim, o que pode ser percebido é que o discurso político conservacionista feito por vários Estados, incluindo o Brasil, na criação dessas áreas não consideram a qualidade da 
medida, mas apenas sua quantificação, o que possibilita dizer que cumpriram as metas estabelecidas e são países preocupados com o meio ambiente, contudo, cumpre ressaltar que o simples estabelecimento de áreas de proteção não constituem o objetivo da meta 11, mas a criação dessas áreas devem representar efetivamente avanços na proteção dos ecossistemas presentes não somente naquela área, mas como essa preservação vai beneficiar as áreas ao redor, o que não se enxerga no caso brasileiro.

Atualmente, somente 0,19\% (12.144,12 hectares) dos recifes de coral de águas profundas estão dentro de áreas protegidas, diferentemente dos recifes de coral de águas rasas que são mais protegidos (76.556,8 hectares). Já em relação às áreas de manguezais, 120 áreas protegidas que as contêm correspondem a uma área de $12.114 \mathrm{~km}^{2}$, correspondente a $87 \%$ do ecossistema de todo o Brasil.

Embora haja números considerados positivos, é necessário manter esse percentual de proteção em vista ao não retrocesso da proteção ambiental, o que não se daria com a revogação das Resoluções n.284/2001, n.302/2002 e n.303/2002 do CONAMA, ensaiadas pelo atual Ministro do Meio Ambiente, Ricardo Salles, no início do mês de outubro de 2020, felizmente suspensas por decisão da Ministra Rosa Weber, evidenciando os posicionamentos contraditórios da gestão ambiental no país em detrimento do meio ambiente.

Outro relevante dado contido no sexto relatório nacional, ainda sobre áreas de manguezais, reside em sua modificação por empreendimentos de carcinicultura que experimentou um aumento entre os anos de 2013 e 2016. Os números mais atuais apontam que mais de 36.000 hectares de manguezais foram convertidos em tanques de cultivos de camarão, dos quais $99,9 \%$ estão localizados em unidades de conservação de uso sustentável, especialmente em APAs (BRASIL, 2020, p. 50). Dessa forma, constata-se que havendo a sobreposição de áreas protegidas classificadas como de uso sustentável, onde atividades econômicas são permitidas, desde que compatíveis com a conservação ambiental, corre-se o risco do comprometimento do seu objetivo, pois não existem parâmetros para se verificar na prática até que ponto essas atividades são desenvolvidas em compatibilidade com a conservação ambiental. Um dos principais problemas decorrentes dessa situação reside no comprometimento da participação de povos tradicionais que se utilizam desse meio para sobreviver, comprometendo o ideal de uma gestão participativa nos frutos dos serviços ecossistêmicos amplamente reafirmado pelo Brasil ao longo do relatório, motivo pelo qual a meta que trata dessa participação será analisada individualmente à frente.

\subsection{Uma gestão participativa e a análise da Meta 14}

Uma das mais relevante metas aborda a restauração e a preservação de ecossistemas provedores de serviços ecossistêmicos ligados à água, contribuindo para a saúde, meios de vida e bem-estar de "mulheres, povos e comunidades tradicionais, povos indígenas e comunidades locais, e de pobres e vulneráveis" podendo aqui se fazer uma relação com a meta 18 , determinando que até 2020 , os “conhecimentos, inovações e práticas tradicionais dos povos indígenas, produtores rurais familiares e comunidades tradicionais relevantes para a conservação da biodiversidade", bem como o seu uso sustentável, serão respeitados e integrados nas ações da CDB (BRASIL, 2020, p. 61,72). Ressalta-se que no texto do sexto relatório nacional, em conjunto, são chamados de PCTAF (povos tradicionais e comunidades e produtores rurais familiares). 
Tais metas traduzem a grande aposta inicial do Brasil na implementação de todas as metas de Aichi no território interno: uma gestão participativa, inclusive nos benefícios ecossistêmicos. O objetivo de todas as iniciativas nesse sentido tende a tornar a preservação ambiental a máxima do seu trabalho e assim todos os envolvidos saem ganhando, sobretudo com o fortalecimento da economia do país, por meio de um diálogo entre diferentes setores sociais e econômicos.

Em inédito cruzamento de dados feitos pelo Ministério Público Federal contidos em cadastros governamentais tais como Incra, Funai, ICMBIO E CadÚnico, fora constatada a existência, por intermédio do critério do autorreconhecimento, de 650.234 famílias brasileiras que se declaram como povo ou comunidade tradicional (PAULO, 2019), considerados, nos termos do inciso I, Art. $3^{\circ}$ do Decreto $n^{\circ}$ 6.040, de 7 de fevereiro de 2007 que estabeleceu a Política Nacional de Desenvolvimento Sustentável de Povos e Comunidades Tradicionais - PNPCT como:

Art. $3^{0}$ Para os fins deste Decreto e do seu Anexo compreende-se por:

I - Povos e Comunidades Tradicionais: grupos culturalmente diferenciados e que se reconhecem como tais, que possuem formas próprias de organização social, que ocupam e usam territórios e recursos naturais como condição para sua reprodução cultural, social, religiosa, ancestral e econômica, utilizando conhecimentos, inovações e práticas gerados e transmitidos pela tradição (Brasil, 2007).

Dado interessante contido nos dados fornecidos pelo MPF diz respeito ao Estado do Pará que reúne em seu território 20\% dessas famílias, sendo o Estado brasileiro com maior concentração desses povos, das quais 50.314 são famílias ribeirinhas, 11.826 extrativistas e 40.123 pescadores artesanais. Além disso, o Estado do Amazonas possui a maior concentração de povos indígenas (43.264) e a Bahia os quilombolas, com 43.009 (PAULO, 2019).

É de se esperar que em um país que abrange grande parcela da biodiversidade do mundo seu potencial seja reconhecido, pois seus costumes e conhecimentos desses povos podem guiar o desenvolvimento e aperfeiçoamento de novas tecnologias para o tratamento ambiental. Tal a relevância de sua participação para a implementação das metas de biodiversidade que o sexto relatório nacional reserva uma seção própria para informar de que forma o país está aproveitando os conhecimentos tradicionais para o alcance de cada uma das vinte metas, valendo destacar as que envolvem a proteção da biodiversidade marinha, analisadas no presente trabalho.

Não é necessário grande esforço para entender que grande parcela dos PCTAF são dependentes da atividade pesqueira para sua subsistência e renda, cuja preservação dos estoques pesqueiros representam a estabilidade social e econômica dessas comunidades (BRASIL, 2020, p. 141). O manejo do pirarucu tem sido uma importante ação autorizada pelo IBAMA em 23 unidades de conservação do Amazonas, consistindo na adoção de técnicas de pescadores regionais do Médio Solimões e sistematizadas por técnicos da reserva de Desenvolvimento Sustentável Mamirauá (BRASIL, 2020, p. 142). Tal iniciativa tem auxiliado na recuperação de estoques de pirarucu com a limitação da pesca em $30 \%$ dos estoques, gerando renda a esses povos tradicionais. 
Dados contidos no sexto relatório nacional enviado à secretaria da CDB apontam que a relevância do PCTAF também está presente na criação de áreas protegidas, sobretudo Reservas Extrativistas (RESEX) e Reservas de Desenvolvimento Sustentável (RDS). Segundo dados do ICMBio (BRASIL apud ICMBio, 2019, p. 149) cerca de 61.000 famílias vivem em 77 UCs de uso sustentável e os recursos hídricos constituem um bem de uso coletivo, assim como a área que em modo geral é grande, o que acaba por se tornar a preservação de corpos d'água e nascentes a prioridade desses povos, por serem áreas de preservação permanente. Uma campanha iniciada em 2004 pelo Instituto Socioambiental - ISA intitulada Campanha Y'Ikatu Xingu, no entorno do Parque Indígena do Xingu, visa mitigar o impacto da agricultura na bacia do rio Xingu por intermédio da colaboração multissetorial por meio do reflorestamento de matas ciliares e áreas de preservação permanente e, como fruto dessa iniciativa, até 2018 já haviam sido plantados aproximadamente 3.800 hectares no entorno do Parque indígena do Xingu se utilizando da técnica "muvuca mecanizada".

Embora os exemplos mencionados acima constituam importantes iniciativas de maneira a integrar o PCTAF aos avanços do país no sentido de preservação da biodiversidade, ainda existem muitos desafios a serem superados. Conflitos envolvendo a propriedade e a utilização de recursos hídricos estão entre eles, repercutindo também em forma de disputas políticas, nas quais por vezes os direitos à terra e recursos naturais, bem como os interesses desses povos são calados em detrimento dos interesses de setores econômicos mais fortes que são constantemente protegidos pelo Governo.

Se não bastasse isso, também precisam lidar muitas vezes com a omissão do Poder Público em promover ações efetivas de restauração e preservação de seus territórios. Com isso, percebe-se que a participação desses povos na gestão ambiental bem como ao acesso aos benefícios dos serviços ecossistêmicos ainda se mostra incipiente.

\section{Conclusĩo}

São vários os desafios a serem enfrentados pelo Brasil para superar o momento crítico na conservação da biodiversidade marinha em que está mergulhado. Embora existam avanços nos resultados de implementação das metas globais e nacionais de Aichi 2011-2020 estabelecidas durante a $10^{\circ}$ reunião das Partes - COP 10, órgão diretor da Convenção sobre Diversidade Biológica, em relação às metas anteriores, observa-se que o País está cometendo muitos erros do passado, comprometendo a eficácia de sua implementação.

Segundo dados gerais presentes no sexto relatório nacional, referentes ao monitoramento das ações do plano de ação nacional para a biodiversidade, constata-se que apenas $12 \%$ das ações foram concluídas, $54 \%$ estão em implementação, $15 \%$ em fase inicial ou em planejamento e $7 \%$ ainda não foram iniciadas. Dessas, $51 \%$ das ações foram consideradas eficientes, $25 \%$ consideradas parcialmente eficientes e $3 \%$ ineficientes. O percentual não avaliado foi de $12 \%$ ao total.

No ano limite para o cumprimento de tais metas, esperavam-se resultados mais expressivos, aptos a servirem de ponta pé inicial para novas medidas para a próxima década a serem tomadas na próxima COP, prevista inicialmente para outubro de 2020, em Kunming, 
na China, mas que por conta da pandemia mundial do COVID-19, foi remarcada para maio de 2021 na mesma cidade. Entretanto, cada vez mais são noticiados desastres ambientais sob a inércia do Governo em restaurar os ecossistemas perdidos, sem levar em consideração os interesses de grupos tradicionais, em clara contradição com o objetivo de gestão participativa e distribuição equitativa dos frutos advindos de serviços ecossistêmicos marinhos.

A título de exemplo, há o derramamento de óleo bruto ocorrido na costa brasileira em 2019, alcançando a faixa litorânea de $4.334 \mathrm{~km}$ em 11 estados do Nordeste e Sudeste, 120 municípios e 724 localidades até 22 de novembro de 2019 (LOPES PENA et al., 2020, p.1) sendo considerado o maior desastre desse tipo da história do país, causando incontáveis prejuízos à biodiversidade marinha existente ali, comprometendo a subsistência de muitos povos tradicionais que se utilizavam daqueles recursos naturais, entre outros problemas, como questões relacionadas à saúde e responsabilidade do Estado, formalizando o Plano Nacional de Contingência para incidentes de poluição por óleo em Águas sob Jurisdicional após 41 dias do desastre.

Saltam aos olhos que as consequências decorrentes de um desastre dessa magnitude são sentidas em maior escala pelos povos tradicionais próximos, cujos pleitos ao Poder Público foram silenciados e vendo seu meio de subsistência em risco, para limpar as áreas afetadas, expuseram-se aos mais diversos elementos carcinógenos, comprometendo a própria saúde. Além disso, destacam-se a contaminação sofrida pelas espécies marinhas expostas ao óleo, culminando na redução de $80 \%$ a $100 \%$ das vendas desses espécimes entre a segunda quinzena de outubro e a primeira semana de novembro, em 2019, em clara evidência dos impactos socioeconômicos sofridos (ARAÚJO et al., 2020)

Fatos como esse só reforçam que a gestão ambiental no Brasil continua sendo ineficiente e quase sempre influenciada por fatores políticos e econômicos, sem levar em consideração a importância da preservação ambiental em si. Traduz- se assim a importância, mais do que nunca, da efetivação do direito fundamental constitucional do ser humano ao meio ambiente ecologicamente equilibrado, consagrados no Art. 225, ligados à noção de uma equidade intergeracional, mas também entendendo que os ecossistemas marinhos e as espécies que os integram merecem proteção, em uma relação de interdependência.

Se fatores políticos prejudiciais não forem abandonados dando lugar à incorporação dessa consciência coletiva da importância de preservar a biodiversidade marinha por intermédio do respeito aos mais diferentes meios de vida existentes em um país megadiverso como o Brasil, metas tais como as de Aichi poderão ser renovadas e repensadas incontáveis vezes, a população brasileira continuará obrigada a conviver com desastres e grandes perdas ambientais, prenúncios de um futuro nebuloso que aguarda a comunidade global.

\section{REFERÊNCIAS}

6th National Report for the Convention on Biological Diversity. The clearing-house mechanism of the convention on biological diversity information submission service, 2020. Disponível em: $<$ https://chm.cbd.int/database/record?documentID=249832>. Acesso em: 02 nov. 2020. 
ARAÚJO, M. E. et al. (2020). Pescadores artesanais, consumidores e meio ambiente: consequências imediatas do vazamento de petróleo no Estado de Pernambuco, Nordeste do Brasil. Cad. Saúde Pública vol.36 no.1 Rio de Janeiro 2020 Epub 20, 2020. Disponível em: <https:/www.scielo.br/scielo.php?pid=S0102- 311X2020000100301\&script $=$ sci_arttext\&tlng=pt $>$. Acesso em: 05 nov. 2020.

BRASIL. Constituição (1988). Constituição da República Federativa do Brasil de 1988. Brasília, DF: Planalto [2020]. Disponível em: <http://www.planalto.gov.br/ccivil_03/constituicao/constituicao.htm>. Acesso em: 14 set. 2020.

BRASIL. Decreto no 6.040, de 7 de Fevereiro de 2007. Brasília, DF: 2007. Disponível em: <http://www.planalto.gov.br/ccivil_03/_ato2007-2010/2007/decreto/d6040.htm>. Acesso em: 05 nov. 2020.

BRASIL, 2010. MMA - Ministério do Meio Ambiente. Disponível em: <https://www. mma.gov.br>. Acesso em: 10 set. 2020.

BRASIL, 2020. MMA - Ministério do Meio Ambiente. Disponível em: <https://www. mma.gov.br/biodiversidade/convenção-da-diversidade-biológica/estratégia-e-plano-de-ação-nacionais-para-a-biodiversidade- epanb/item/7538-diálogos-sobre-biodiversidade-construindo-a-estratégia-brasileira-para-2020.html >. Acesso em: 30 set. 2020.

BRASIL. STF - Supremo Tribunal Federal. Inteiro teor do Acórdão da ADI 4.066. ADI N4.066 (0001503-89.2008.1.00.0000). Associação Nacional dos Procuradores do Trabalho - ANPT. Relatora: Ministra Rosa Weber. 24 de Agosto de 2017. Disponível em: <http:// redir.stf.jus.br/estfvisualizadorpub/jsp/consultarprocessoeletronico/ConsultarProcessoEletronico.jsf?seqobjetoincidente $=2607856>$. Acesso em: 16 set. 2020.

BRASIL. STF - Supremo Tribunal Federal. Inteiro teor do Acórdão do RE 835558. RE No83.5558 (Recurso Extraordinário 83.558 São Paulo). Ministério Público Federal. Relator: Ministro Luiz Fux. 09 de Fevereiro de 2017. Disponível em:

$<$ http://redir.stf.jus.br/estfvisualizadorpub/jsp/consultarprocessoeletronico/ConsultarProcessoEletronico.jsf? seqobjetoincidente=4630090>. Acesso em: 16 set. 2020.

Diálogos sobre biodiversidade: Construindo a estratégia brasileira para 2020. Ecoteca Digital Terra Brasilis, 2020. Disponível em: <http://www.terrabrasilis.org.br/ecotecadigital/index.php/estantes/gestao/1874- dialogos-sobre-biodiversidade-construindo-a-estrategia-brasileira-para-2020>. Acesso em: 23 out. 2020.

EPANB - Estratégia e Plano de Ação Nacionais para a Biodiversidade. Ministério do Meio Ambiente - MMA, 2020. Disponível em: <https://www.mma.gov.br/epanb>. Acesso em: 03 nov. 2020. 
Estratégia e Plano de Ação Nacionais para a Biodiversidade. MMA, sem data. Disponível em: <https://www.mma.gov.br/biodiversidade/conven $\% \mathrm{C} 3 \% \mathrm{~A} 7 \% \mathrm{C} 3 \% \mathrm{~A} 3 \mathrm{o}-\mathrm{da}$-diversidade-biol $\% \mathrm{C3} \% \mathrm{~B} 3$ gica/estrat $\% \mathrm{C} 3 \% \mathrm{~A} 9$ gia-e-plano-de-a $\% \mathrm{C3} \% \mathrm{~A} 7 \% \mathrm{C} 3 \% \mathrm{~A} 30-$ nacionais-para-a-biodiversidade-epanb.html>. Acesso em: 03 nov. 2020.

FONTES, A. G. Análise da implementação das metas nacionais e de Aichi de conservação da biodiversidade marinha brasileira. Uniceub, Brasília, 12 de fev. de 2016. Disponível em: <https://repositorio.uniceub.br/jspui/handle/235/7782>. Acesso em: 05 nov. 2020.

JOLY, C. A. et al. (2019). $1^{\circ}$ Diagnóstico Brasileiro de Biodiversidade e Serviços Ecossistêmicos. Editora Cubo, São Carlos pp.351. Disponível em: $<$ https://doi.org/10.4322/97885-60064-88-5>. Acesso em: 04 nov. 2020.

LOPES PENA, P. G. et al. (2020). Derramamento de óleo bruto na costa bresileira em 2019: emergência em saúde pública em questão. Cad. Saúde Pública vol. 36 no.2 Rio de Janeiro 2020 Epub Jan 3, 2020. Disponível em: <https://www.scielo.br/scielo.php?scrip$\mathrm{t}=$ sci_arttext\&pid=S0102-311X2020000200501>. Acesso em: 05 nov. 2020.

Metas de Aichi: Situação Atual no Brasil. WWF, 2020. Disponível em: < https://www. wwf.org.br/informacoes/bliblioteca/?29462/Metas-de-Aichi-Situacao- atual-no- Brasil\#: :text=\%C3\%89\%20um\%20esfor $\%$ C3\%A7o\%20de $\% 20$ revis $\%$ C3\%A3o,de $\% 20$ Pesquisas\%20Ecol\%C3\%B3gicas\%20(IP\%C3\%8A)>. Acesso em: 02 nov. 2020.

MMA - Ministério do Meio Ambiente, 2011. UICN, WWF-BRASIL e IPE. Metas de Aichi: Situação atual no Brasil. Ronaldo Weigand Jr; Danielle Calandino da Silva; Daniela de Oliveira e Silva. Brasília, DF: UICN, WWF-Brasi e IPÊ, 2011. Disponível em: $<\underline{\text { https:// }}$ wwfbr.awsassets.panda.org/downloads/metas_de_aichi_situacao_atual_no brasil_2011 download.pdf.> Acesso em: 02 nov. 2020.

MMA - Ministério do Meio Ambiente, 2016. Em 40 anos, a biodiversidade marinha do planeta foi reduzida à metade. MMA, 16 de set. de 2015. Disponível em: $<$ https://www. wwf.org.br/wwf_brasil/?47822/em-40-anos-a-biodiversidade-marinha-do-planeta-foi-reduzida-a-metade> . Acesso em: 03 nov. 2020.

PAULO, P. P. 650 mil famílias se declaram 'povos tradicionais' no Brasil; conheça os Kalungas, do maior quilombo do país. G1, (s.r), 29 de Out. de 2019, G1 natureza. Disponível em: <https:/g1.globo.com/natureza/desafio- natureza/noticia/2019/10/29/650-mil-familias-se-declaram-povos-tradicionais-no- brasil-conheca-os-kalungas-do-maior-quilombo-do-pais.ghtml>. Acesso em: 05 nov. 2020.

Programa Marinho. WWF, 2020. Disponível em: <https://www.wwf.org.br/natureza_ brasileira/reducao_de_impactos2/programa_marinho/>. Acesso em: 03 nov. 2020. 
ROMA, J. C.; ROMA, A. M. (org). Governança Ambiental no Brasil. Instituições, atores, e políticas públicas. Brasília: Ipea, 2016.

SILVA, A. P. A meta 11 de Aichi e as áreas marinhas protegidas em grande escala: proteção ambiental ou oportunismo político?. Revista de Direito Internacional - UNICEUB, volume 16, Brasília, 2019. Disponível em: <https://www.publicacoesacademicas.uniceub. br/rdi/article/view/6102>. Acesso em: 04 nov. 2020.

TRENNEPOHL, T. D. Manual de Direito Ambiental. São Paulo: Editora Saraiva, 2019. Disponível em:

$<$ https://integrada.minhabiblioteca.com.br/\#/books/9788553616718/>. Acesso em: 14 set. 2020.

Veto do STF a resoluções de Salles é "alívio" para a natureza, diz Molon. Brasil de Fato, 2020. Disponível em: <https:/www.brasildefato.com.br/2020/10/29/veto-do-stf-a-resolucoes-de-salles-e- alivio-para-a-natureza-diz-molon>. Acesso em: 04 nov. 2020.

\section{Aleph Hassan Costa Amin}

Doutorando em Direito pelo Programa de Pós-Graduação em Direito da UFPA. Mestre em Direitos Humanos e Meio Ambiente pela UFPA (PPGD). Graduado em Direito pela Universidade Federal do Pará. E-mail: alephamin@gmail.com

\section{Milena Furtado Farias}

Bacharel em Direito pelo Centro Universitário Metropolitano da Amazônia - UNIFAMAZ. E-mail: milenafurtadofarias@gmail.com

\section{Dielle Alana Albuquerque Carneiro}

Bacharel em Direito pelo Centro Universitário Metropolitano da Amazônia - UNIFAMAZ. E-mail: alanadielle@gmail.com

Submetido em: 6-3-2021

Aceito em: 20-8-2021 